\title{
Spanwise Wing Loads on the Space Shuttle Orbiter during Roll Maneuver
}

\author{
Glen P. Doggett ${ }^{1}$ \\ Boeing, Space Exploration, Houston,TX, 77059
}

\begin{abstract}
Spanwise aerodyanamic loads for the low-Mach, high-attitude portion of ascent for the Space Shuttle Orbiter are presented. In this Mach 0.3 flight regime, also called the roll maneuver, pre-stall and post-stall distributions of aerodynamic wing shear force, bending moment, and torsion moment were obtained from wind tunnel test data and computational fluid dynamics simulations of the Space Shuttle Launch Vehicle. The spanwise loads were computed by integration of surface pressure data. The existing historical operational database of spanwise wing loads for the Orbiter does not cover this low-Mach, high-attitude condition, however for Mach 0.6 low-attitude conditions the experimental and computational results compare well with the operational data which has been validated by past flight measurements. Spanwise load distributions exhibit typical delta-wing characteristics. The computational results capture well the peak loading condition in the pre-stall case, but show more load relief for the post-stall case than was observed in the wind tunnel test data.
\end{abstract}

\section{Nomenclature}

$\alpha \quad=$ angle of attack

$\beta \quad=$ sideslip angle

CFD $=$ computational fluid dynamics

$C_{p} \quad=$ pressure coefficient

$\delta_{e i}, \delta_{e o}=$ inboard and outboard elevon deflection angles, respectively

$M_{\infty} \quad=$ freestream Mach number

mrc $=$ Moment Reference Center

$\mathrm{OADB}=$ Operational Aerodynamic Data Book for Space Shuttle Launch Vehicle

$(\mathrm{X}, \mathrm{Y}, \mathrm{Z})_{\mathrm{o}}=$ Orbiter reference coordinate system (inches)

\section{Introduction}

$\mathrm{T}$ HE Operational Aerodynamic Data Book ${ }^{1}$ (OADB) for the Space Shuttle Launch Vehicle (SSLV) contains distributed pressure coefficient data starting at $M_{\infty}=0.6$ at several discrete Mach numbers through atmosphereic ascent for a small range of angles of attack and sideslip angles that envelopes conditions of the ascent trajectory. This aerodynamic data is used in conjunction with total vehicle force and moment coefficients for integrated trajectory and loads analysis. During the portion of ascent from the lift-off up to $M_{\infty}=0.6$ no detailed distributed pressure data was deemed necessary due to expected low dynamic pressure and negligible effects of compressibility in that flight regime. However, due to the lower velocity in that portion of the trajectory, the flight vehicle attitude is more sensitive to atmospheric winds which may induce large angles of attack and sideslip. This flight regime coincides with the transition of the vehicle from an upright orientation to a belly-up orientation, an event also known as the Roll Maneuver. Althought not encountered in a nominal trajectory, the lack of distributed pressure data and integrated loads analysis at these conditions may result in over conservatism to compensate for the uncertainty in launch decisions in conditions of high atmospheric winds. To increase confidence and reduce uncertainty in launch decisions new distributed pressure data was obtained through computational fluid dynamics (CFD) simulations and wind tunnel tests of the SSLV configuration. This paper presents selected spanwise aerodynamic loads on the Orbiter wing during the Roll Maneuver based on this new data for pre-stall and post-stall flight attitudes.

\footnotetext{
${ }^{1}$ Aerospace Engineer, Integrated Vehicle Analysis, 13100 Space Center Blvd./Mail Code HB2-20, AIAA Senior
} Member. 


\section{Spanwise Wing Loads}

The Orbiter wing loads are defined with respect to the coordinate system shown in Fig. 1. The spanwise loads presented herein were obtained by surface pressure integration over the portion of the wing from a reference station on the wingspan, $\mathrm{Y}_{0}$, to the tip. The Moment Reference Center, MRC, "walks" along the span with the Orbiter coordinate $\mathrm{Y}_{\mathrm{o}}$ but remains fixed in $\mathrm{X}_{\mathrm{o}}$ and $\mathrm{Z}_{\mathrm{o}}$.

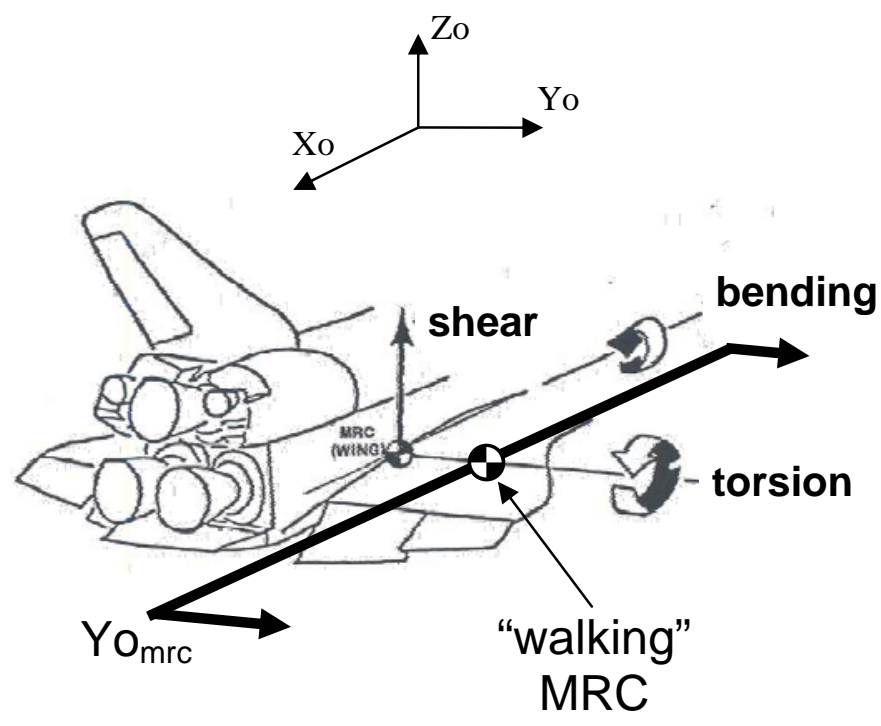

Figure 1. Spanwise aerodynamic loads: shear force, bending moment, torsion moment.

\section{A. Wind Tunnel Test Measured Wing Loads}

During Return to Flight redesign and analysis activities performed for removal of the foam ramp on the bipod attach fitting a wind tunnel test designated IA-700A ${ }^{2}$ was performed in October 2004 at the Arnold Engineering Development Center (AEDC) 16' Transonic Wind Tunnel. The test Mach range from 0.18 to 1.55 covered enveloped both the low-Mach, high-attitude Roll Maneuver conditions as well as the Mach number that typically coincides with maximum dynamc pressure during a nominal ascent trajectory.

The 3\% scale model, designated the 47-OTS model, was refurbished for the IA-700A test. The Orbiter was instrumented with a 3-component strain-gage balance on the right wing, and a set of distributed pressure taps on the left wing. Pressure taps were also located around the fuselage, the vertical tail, and around the external tank. The right wing balance measured total wing shear, bending, and torsion loads, while the pressure taps on the distributed on the left wing were used to determine local spanwise loads. 


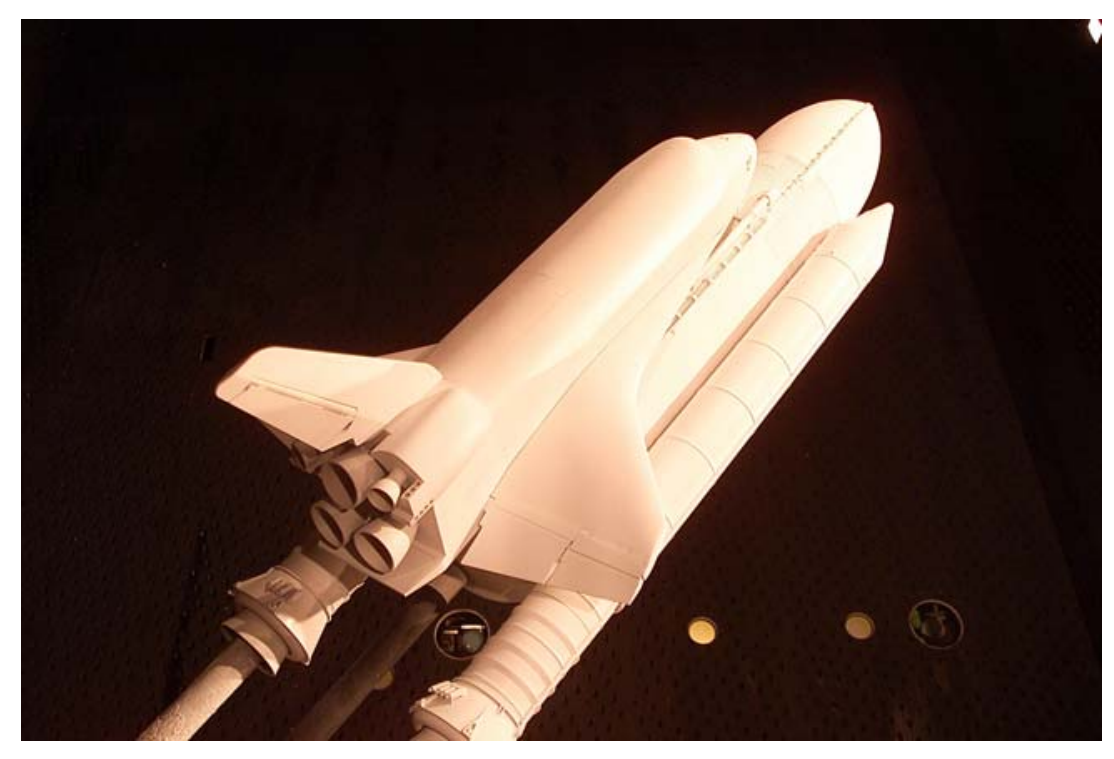

Figure 2. 3\% scale SSLV wind tunnel test model in AEDC 16’T test section.

To perform the pressure integration of the pressure tap data, an approximate surface panel mesh was created based on the coordinates of the pressure taps. First, the pressure tap belts were fit with a cubic spline curve to create the wing sections. Then the wing sections were fit with a linear ruled surface. This simple approximate surface terminates at the final pressure tap belt close to the tip, so a small portion of the wing is truncated at the tip. Pressure data was interpolated from the discrete pressure tap data onto the approximate wing panel mesh for the test conditions of interest. The surface pressure data was integrated using a numerical integration technique from Katz and Plotkin ${ }^{3}$. A picture of the original pressure tap data overlayed onto the splined/ruled surface with the pressure data interpolated is shown in Fig. 3.

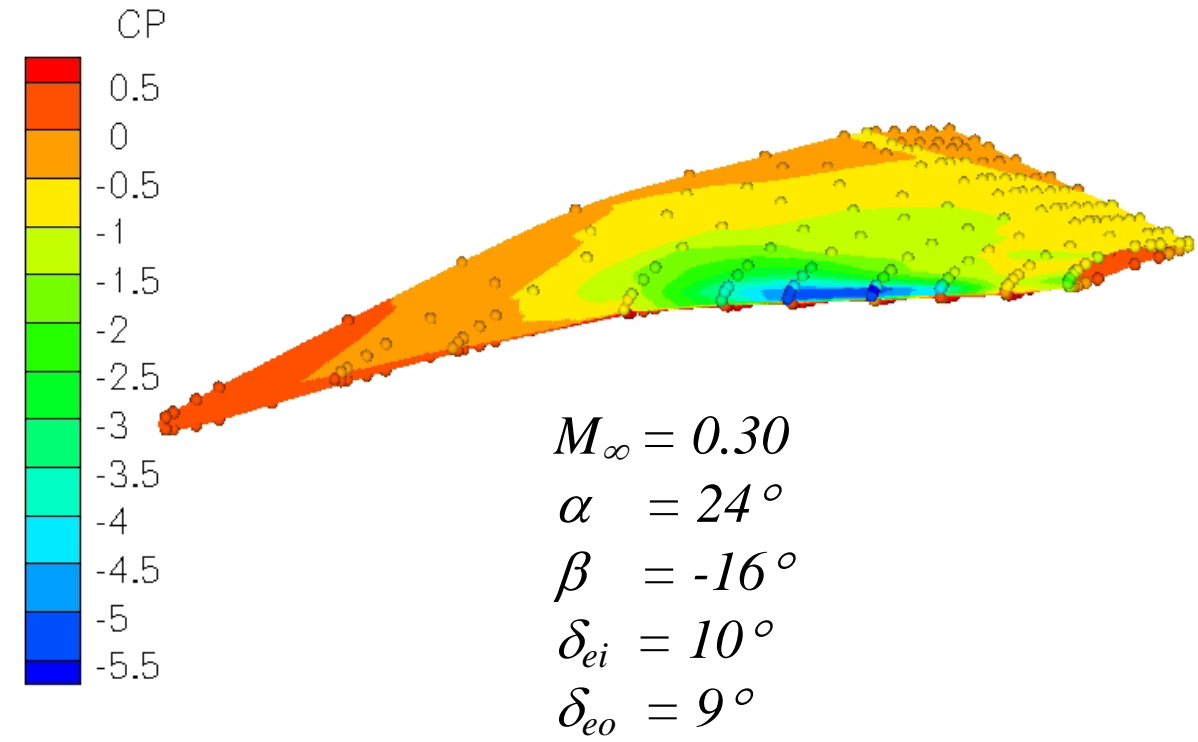

Figure 3. Measured pressure tap data interpolated onto approximate splined/ruled Orbiter left wing surface.

\section{B. CFD-Based Wing Loads}


NASA-JSC has developed an overset structured grid CFD model of the SSLV using Chimera Grid Tools scripts and the OVERFLOW solver ${ }^{4}$. The grid geometry has gone through several revisions to add additional details and to match recent design changes of the vehicle ${ }^{5}$. The CFD solutions presented here were provided by NASA. The surface pressure integration of the spanwise wing loads was performed with a utility developed by NASA-JSC called triqload for pressure integration of overset grids. Figure 4 shows the Orbiter left wing geometry and the span stations used for integrating the surface pressures with the triqload utility.

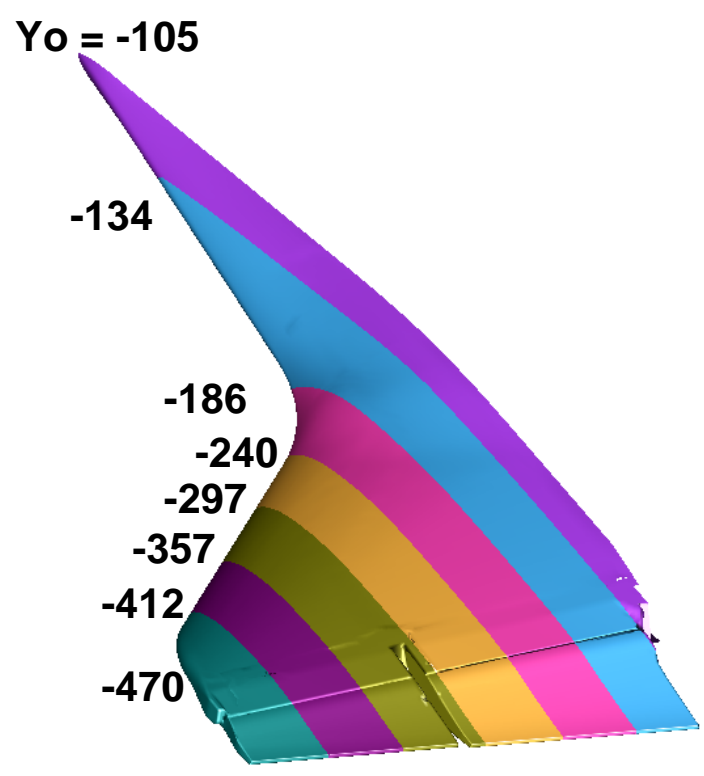

Figure 4. Orbiter left wing geometry and segment breaks used for CFD-based integration of spanwise loads.

\section{Results}

To validate the loads integration methods employed for the IA700 wind tunnel test data and the CFD computations, an initial comparison was made with the historical data in the Space Shuttle Operational Aerodynamic Data Book (OADB). The OADB data is based on past wind tunnel tests which have been validated by flight measurements from the SSLV. In addition to flight pressure measurements on the Orbiter wing, strain gage flight measurements have validated the aerodynamic data and the structural analysis model ${ }^{6}$. The most extreme attitude condition from the OADB was chosen for the comparison case: $M_{\infty}=0.60, \alpha=8^{\circ}, \beta=-8^{\circ}$. This OADB wing loads data is overlayed with the corresponding CFD and IA-700A test data at matching freestream conditions, along with the $M_{\infty}=0.30, \alpha=8^{\circ}, \beta=-8^{\circ}$ condition in Fig. 5. For the $M_{\infty}=0.60$ condition the CFD and IA700 test data copmare well with the OADB data in magnitude and trend. The CFD predicted loads are slightly higher than the OADB and IA700 test data. Note that the IA700 test data is based on a simplified ruled surface that has been truncated at the last pressure tap belt an artifact of which is the shear force coefficient has a zero value just slightly inboard of the actual tip station, so this truncation may account for part of the discrepancy. 


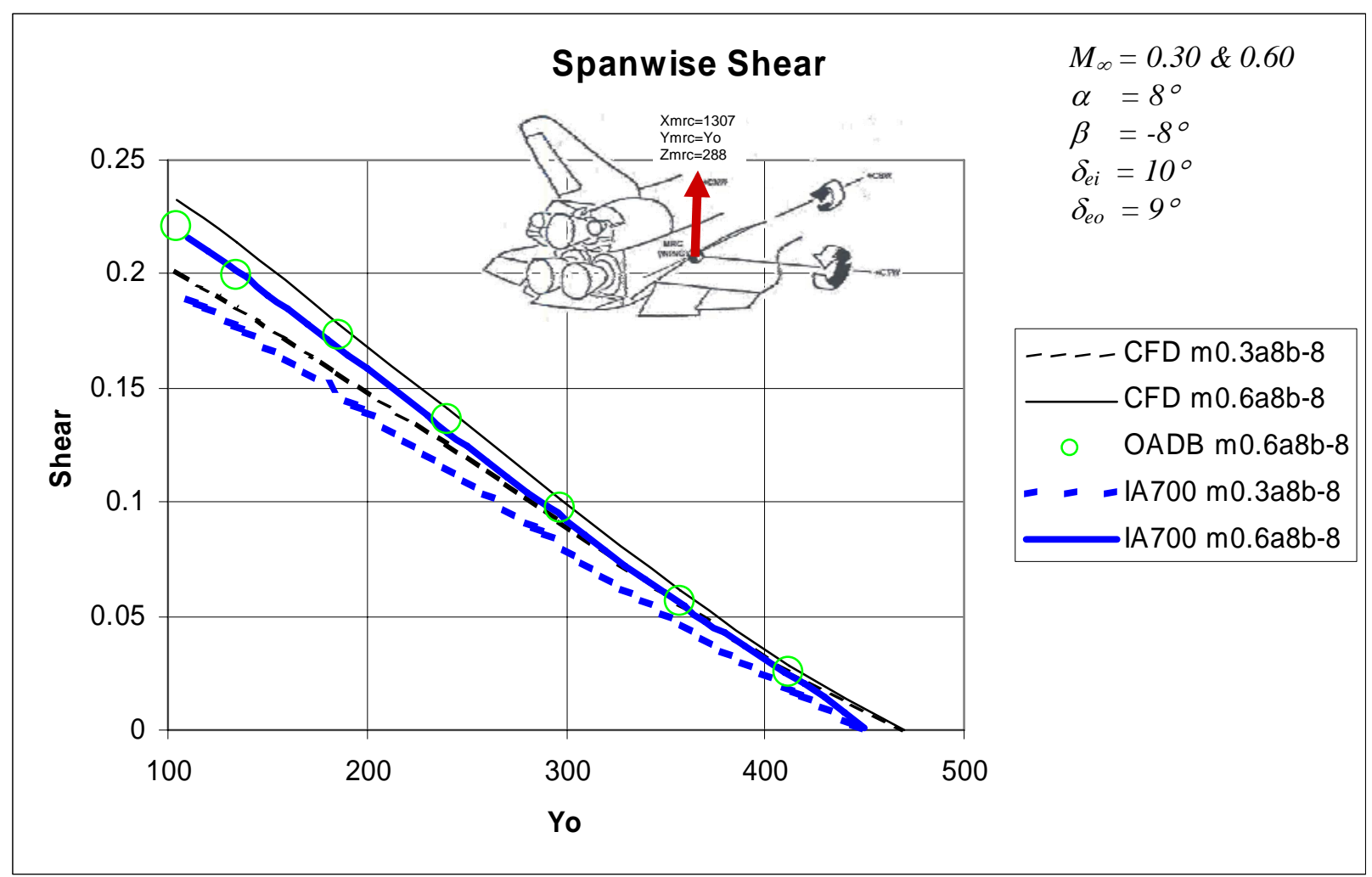

Figure 5a. Spanwise Shear Force Coefficient, OADB, CFD, IA700 comparison case.

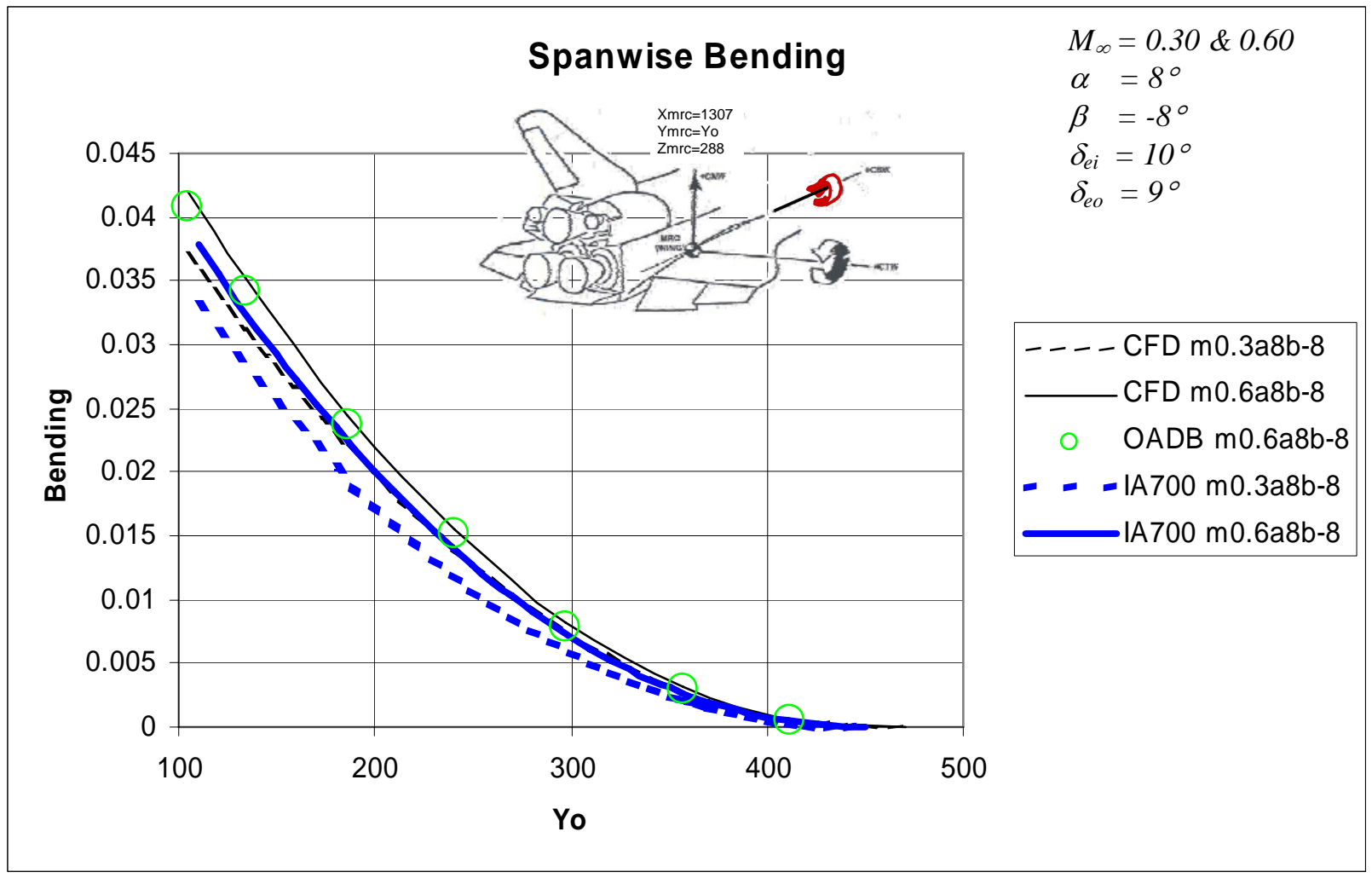

Figure 5b. Spanwise Bending Moment Coefficient, OADB, CFD, IA700 comparison case. 


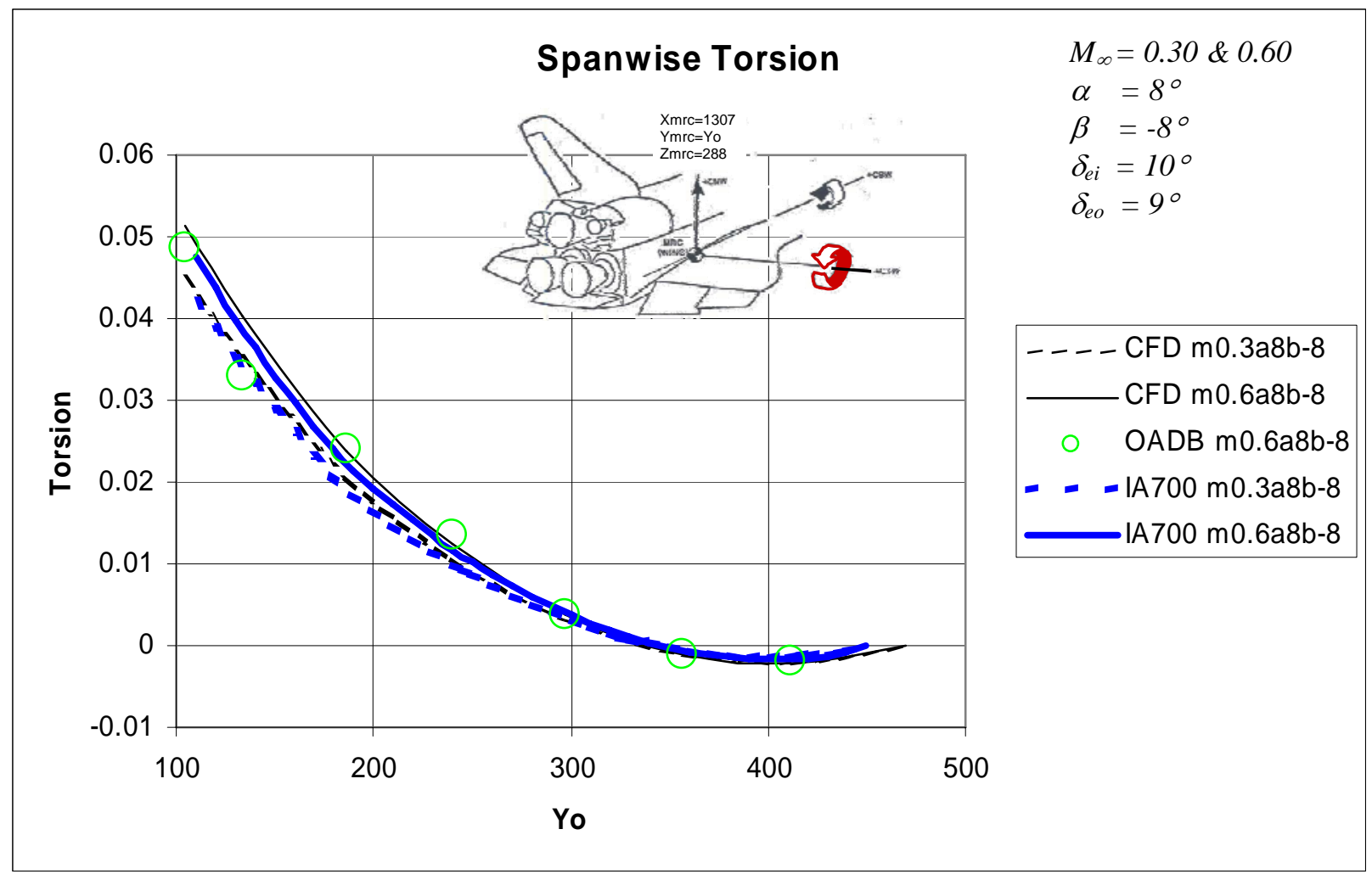

Figure 5c. Spanwise Torsion Moment Coefficient, OADB, CFD, IA700 comparison case.

The new IA700 and CFD Roll Maneuver cases cover more extreme attitudes than the existing OADB, and are shown in Fig. 6 for pre-stall and post-stall angles of attack: with $\alpha=18^{\circ}$ and $\alpha=24^{\circ}$, respectively, for $M_{\infty}=0.30$ and $\beta=-16^{\circ}$. In the pre-stall Roll Maneuver case, the CFD and IA700 data compare very well in total wing loads at the root and in the spanwise trends. However, for the post-stall condition, the CFD results show a larger reduction in shear along the entire span, where the test data shows a smaller region of reduced shear, or a more gradual stall that may have occurred over only a portion of the wing span. 


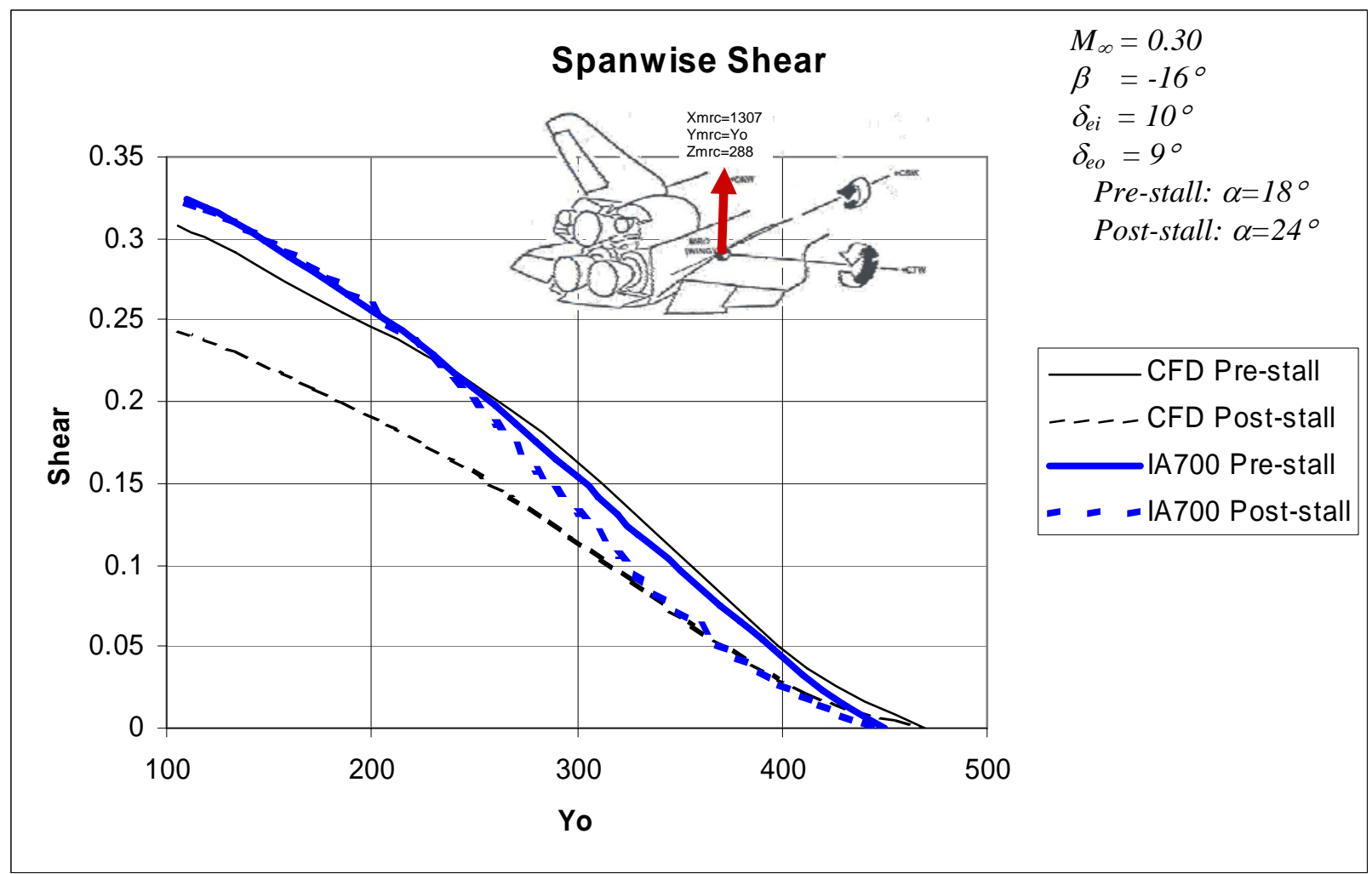

Figure 6a. Spanwise Shear Force Coefficient, CFD, IA700 Roll Maneuver comparison case. 


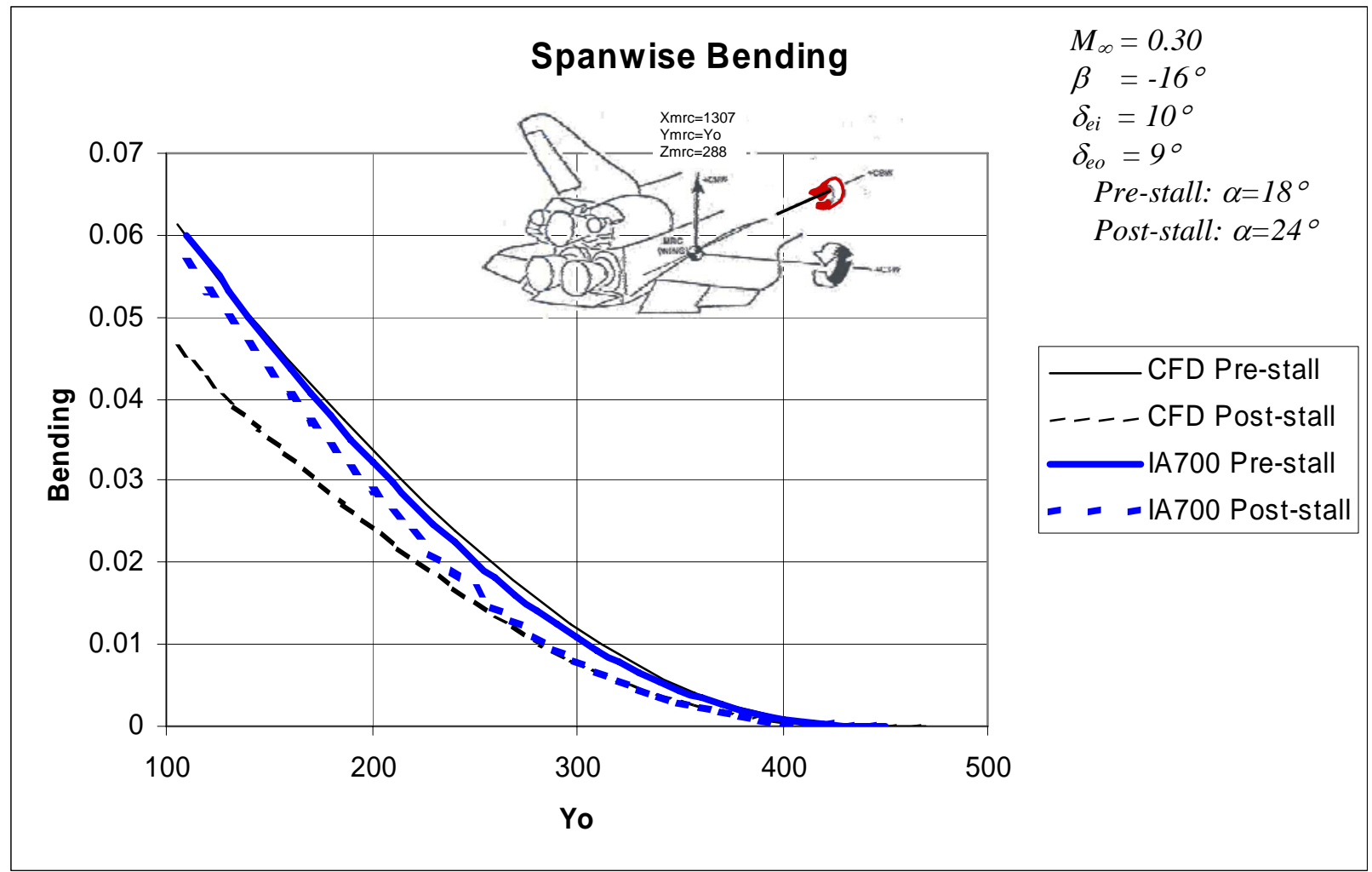

Figure 6b. Spanwise Bending Moment Coefficient, CFD, IA700 Roll Maneuver comparison case.

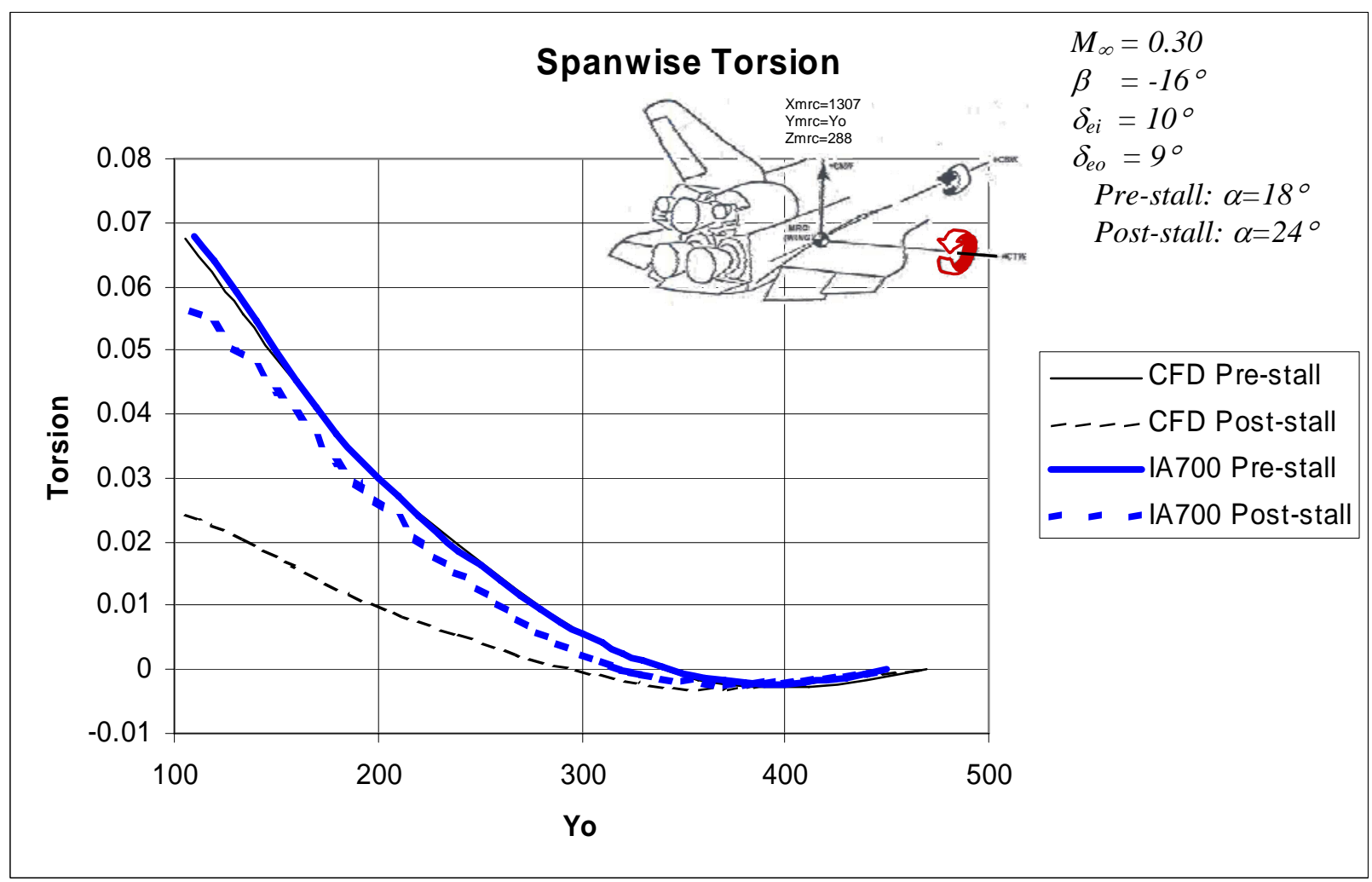

Figure 6c. Spanwise Torsion Moment Coefficient, CFD, IA700 Roll Maneuver comparison case. 
Of most significant concern, the post-stall distributions in the CFD and IA700 data show load relief, and no local increases in shear, bending, or torsion loads. Despite being in the wake of the External Tank and Solid Rocket Boosters, the Orbiter wing exhibits typical delta-wing stall behavior, a notional diagram of which is shown in Fig. 7.

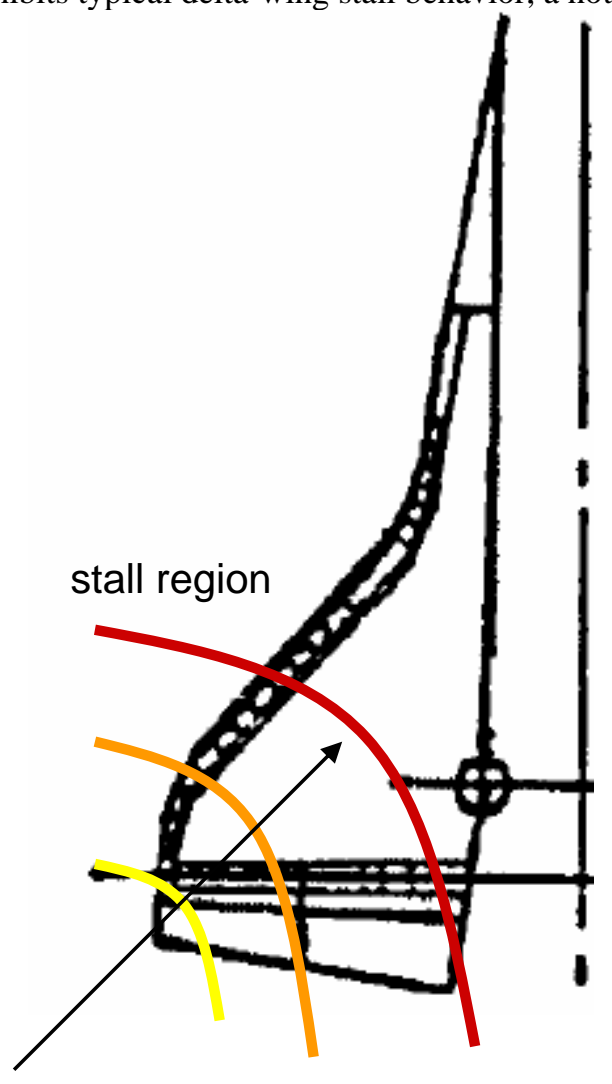

Figure 7. Notional delta-wing stall progression.

The trends of the total wing loads measured from the right wing strain gage and computed by CFD are shown in Fig. 8. The CFD shows a larger reduction in shear load post-stall, while the wind tunnel measurements show a more gradual stall. Both results show good agreement in the peak loading condition. 


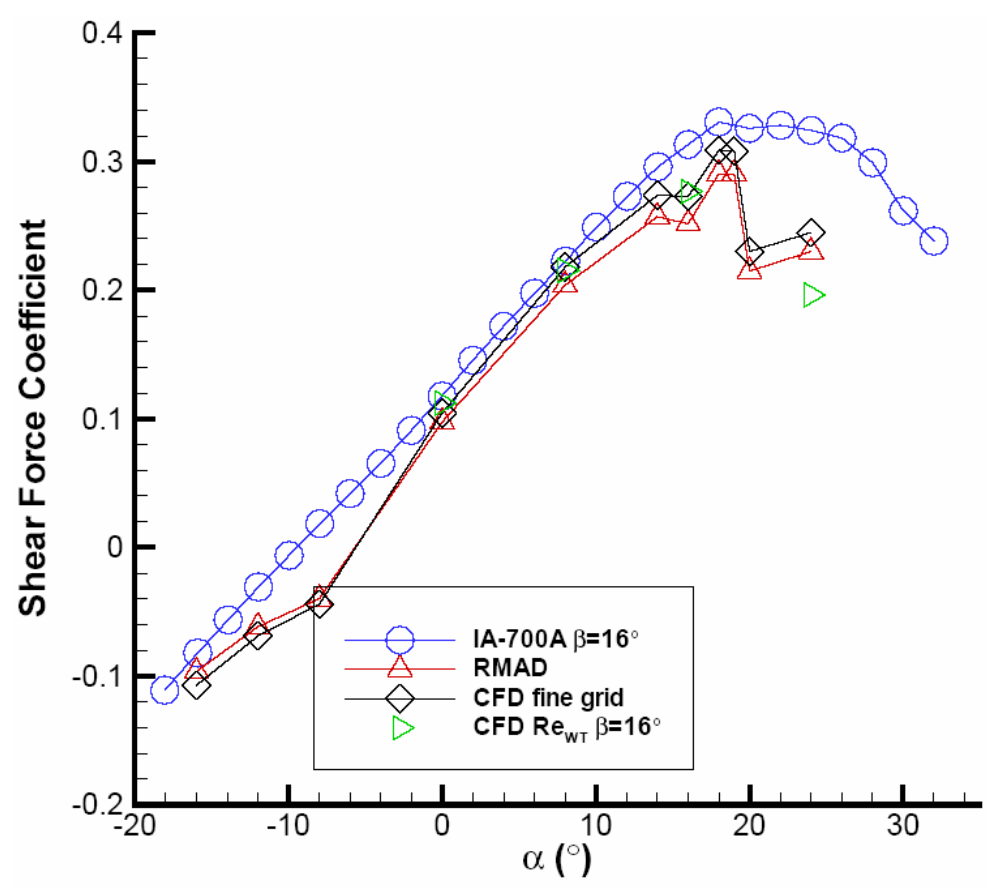

Figure 8. Shear force coefficient versus angle of atttack for Roll Maneuver $M_{\infty}=0.30, \beta=16^{\circ}$.

\section{Conclusion}

The comparisons between the wind tunnel test data and the CFD solutions show excellent agreement in total wing loads and in local spanwise wing loads at large sideslip angles throughout the pre-stall angles of attack for the $M_{\infty}=0.30$ Roll Maneuver flight regime up to the maximum loading condition of the wing. For $M_{\infty}=0.60$ conditions at moderate attitudes the new test data and CFD compare well with the historical operational data based on past wind tunnel and flight test data. The behavior of the Orbiter wing is consistent with typical delta-wing characteristics. The post-stall $M_{\infty}=0.30$ loads predicted by the CFD were comparatively lower than the loads measured in the wind tunnel test by both strain gage measurements and integration of distributed pressure data. The inherent unsteadiness of the separated flow may introduce some inconsistency in comparison of the computed results from one single iteration with time-averaged test data. Also, the CFD grid clustering is typically concentrated at the surface to resolve the attached-flow boundary layer, while on a delta wing in the stall regime a large contribution to the wing loads is derived from an off-surface vortex core, which may require additional grid resolution off the surface of the wing. The new aerodynamic data for the $M_{\infty}=0.30$ Roll Maneuver will be useful in performing additional loads analysis of the vehicle in this low-Mach, high-attitude flight regime that will increase knowledge of the response of the vehicle to low-altitude atmospheric winds, and ultimately increase confidence in launch day decisions.

\section{Acknowledgments}

The author would like to thank the following for their contributions to this work: Ray Gomez and Darby Vicker of NASA-JSC, EG3 for providing the CFD solutions of the SSLV and the triqload pressure integration utility; Dr. Chung-Jin Woan of Boeing Phantom Works, Huntington Beach for performing the CFD pressure integrations; Lung-Chuen Wong of Boeing NASA Systems, Houston for his guidance and support; the staff at the 16' Transonic Tunnel at Arnold Engineering Development Center (AEDC) for support in conducting the IA-700A wind tunnel test. 


\section{References}

1. Space Shuttle Transportation System, Operational Aeodynamic Design Data Book, STS85-0118-1 Change 10, Vol. 5, Chapter 5.1.8.3, Boeing, NASA Systems, August, 2001.

2. Doggett, G., Wong, L., and Lai, S., "Post-test data analysis report for IS-700A and IA-700B Wind Tunnel Tests," SE07HOU166, Boeing Houston, TX, TBD.

3. Katz, J. and Plotkin, A., Low-Speed Aerodynamics From Wing Theory to Panel Methods, McGraw Hill, New York, 1991.

4. Gomez, R., Ma, E., "Validation of a Large-Scale Chimera Grid System for the Space-Shuttle Launch Vehicle,” AIAA Paper 94-1859-CP

5. Gomez, R., Vicker, D., Rogers, S., Aftosmis, M., Chan, W., Meakin, R., Murman, S., "STS-107 Investigation Ascent CFD Support,” AIAA Paper 2004-2226, 34 ${ }^{\text {th }}$ AIAA Fluid Dynamics Conference and Exhibit, June 28 - July 1, 2004, Portland, Oregon.

6. Gibson, E. and Ung, V., Shuttle Wing Shear, Bending, Torsion Loads Calculated Using Strain Gage Data, AIAA Paper 95-1201, 36 ${ }^{\text {th }}$ AIAA/ASME/ASCE/AHS/ASC Structures, Structural Dynamiocs and Materials Conference April 10-12, 1995, New Orleans, LA 